\title{
Pulmonary Antioxidant Enzyme Maturation in the Fetal and Neonatal Rat. I. Developmental Profiles
}

\author{
A. KEITH TANSWELL ${ }^{(35)}$ AND BRUCE A. FREEMAN ${ }^{(36)}$ \\ Department of Paediatrics, University of Western Ontario, London, Canada and Department of Medicine, Duke \\ University Medical Center, Durham, North Carolina, USA
}

\begin{abstract}
Summary
Neonatal, adult, and fetal rat lungs of 18,20 , and $22 \mathrm{~d}$ gestation from four to six litters were examined for cytochrome oxidase, glucose-6-phosphate dehydrogenase, catalase, glutathione peroxidase, copper-zinc and manganese superoxide dismutase activities. All results were corrected for the contribution of enzymes in blood that contaminate homogenates. Because lung protein/ DNA ratios and body water change significantly with gestational age, enzyme activities were expressed as U/mg DNA. All activities were low in $\mathbf{d} 18$ lung and increased with advancing gestational age. Only catalase and copper-zinc superoxide dismutase increased activity in response to air breathing, suggesting that maturation of the antioxidant enzyme system is virtually complete before delivery. Activities of glucose-6-phosphate dehydrogenase, catalase, glutathione peroxidase, and manganese superoxide dismutase were higher in neonatal than in adult lung.
\end{abstract}

Abbreviations

BPD, bronchopulmonary dysplasia

CAT, catalase

CYT OX, cytochrome oxidase

G-6-PD, glucose-6-phosphate dehydrogenase

GPX, glutathione peroxidase

HBSS, Hank's balanced salt solution

SOD, superoxide dismutase

Premature delivery and exposure to elevated concentrations of inspired oxygen may be significant risk factors $(8,14)$ for the development of BPD. Successful adaptation to a hyperoxic environment by young or adult animals of a number of species is associated with increased intrapulmonary concentrations of enzymes with antioxidant protective functions $(6,22)$.

There is evidence that the initial cell damage observed in hyperoxic tissue occurs as a consequence of increased production of intracellular oxygen radicals by cell constituents, including mitochondria and endoplasmic reticulum $(11,20,29)$. Cell survival requires the cell either to have adequate antioxidant defense mechanisms or to rapidly respond to oxidant stress by an increases of such mechanisms that can detoxify reduced species of oxygen and by-products. Because production of superoxide and hydrogen peroxide increases in lung cells as a function of oxygen concentration $(11,20,29)$, the 5-fold increase in arterial oxygen tension which occurs after delivery (23) would be expected to pose significant oxidant stress to the normal neonatal lung, especially since an acute 5-fold increase in inspiratory oxygen concentration is lethal to adults of most species (20). The normal term newborn human infant, however, shows no clinical evi- dence of pulmonary oxidant damage, suggesting that adequate antioxidant defences have been induced in the lung before delivery. Gestation-dependent increases in antioxidant enzyme activities have been reported for placenta (30) and for catalase, but not GPX or SOD $(18,34)$ in liver. In rat brain GPX activity is similar, at birth, to that observed in adults whereas SOD activities are low compared with the adult (19).

Postnatal changes in pulmonary antioxidant enzyme activities have been comprehensively documented $(5,15,33)$ whereas, to our knowledge, antenatal changes have only been studied in two reports $(1,31)$ which did not examine changes in manganese SOD. Subsequent observations suggest manganese SOD may be of critical importance in antioxidant defence $(6,11)$. Reduced concentrations of pulmonary antioxidant enzymes before term could account, in part, for the increased susceptibility of prematurely born infants to BPD $(8,14)$ whereas differences between neonatal and adult enzyme activities may contribute to the increased tolerance of newborn animals to hyperoxic environments normally lethal to adults of the same species (22).

In this report we examined rat fetal lung antioxidant enzyme activities at the late pseudoglandular (d 18), late canalicular (d $20)$, and late terminal sac (d $22=$ term) stages of fetal lung development (4). We then compared these values with those from 3 -d old neonatal rats and young adult females.

\section{MATERIALS AND METHODS}

Female Sprague-Dawley white rats (Charles River Inc., St. Constant, Quebec, Canada) were mated with male hooded rats and sacrificed after timed gestations of 18,20 , and $22 \mathrm{~d}$, or allowed to deliver. The pups were sacrificed at $3 \mathrm{~d}$ of age. Young adult virgin female Sprague-Dawley rats (250-275 g) were sacrificed as controls $(n=5)$. Adult animals were allowed free access to water and food (Purina Lab Chow 5010). The fetuses were removed under chloroform anesthesia and immediately decapitated to prevent respiration. The pups were anesthetised with chloroform and then decapitated. Blood was allowed to drain from the transected neck into heparinized tubes, then sonicated before enzyme analyses. The carcasses were counted, opened from diaphragm to neck, and the heart and lungs removed en bloc and placed in HBSS at $4^{\circ} \mathrm{C}$. The heart and major airways were dissected off, and the lungs from each litter pooled and blotted. The lungs were then minced with scissors and washed three times in HBSS to remove red cells, then blotted and weighed. This material was then finely minced and homogenized in $1.5-3.0 \mathrm{ml}(8.5 \mathrm{ml}$ for adults) $50 \mathrm{mM}$ potassium phosphate/ $0.1 \mathrm{mM}$ EDTA pH 7.8 for $30 \mathrm{~s}$ on ice with a Polytron (Brinkmann Instruments, Inc., Wesbury, NY), then centrifuged at 1000 $g$ for $10 \mathrm{~min}$ and the supernatant collected and stored at $-70^{\circ} \mathrm{C}$ 
before analysis. Freezing and thawing samples once was shown not to affect enzyme activities.

Protein content was estimated by the Lowry method (16) after protein was solubilized by heating the samples at $75^{\circ} \mathrm{C}$ for 15 min in $2 \mathrm{M}$ sodium hydroxide and the DNA content measured fluorimetrically (9). CYT OX (EC 1.9.3.1.), a mitochondrial marker enzyme, was measured as described by Sottocasa et al. (26), CAT (EC 1.11.1.6.) as described by Bergmeyer (2), GPX (EC 1.11.1.9.) as described by Beutler (3), G-6-PD (EC 1.1.1.49.), and CuZn SOD and Mn SOD (EC 1.15.1.1.) as described by Hayatdavoudi et al. (13).

Contamination of homogenates with blood was estimated by a modification (27) of the method described by Cross et al. (7). The contamination of samples which had been minced and washed before homogenization was compared with control samples from the same three litters in a separate series of experiments. Enzyme activities in the lung were corrected for the contribution of total activity due to blood contamination.

Litters from five to seven animals were sacrificed for each age group and statistical comparisons made by analysis of variance. All results are presented as $\bar{x} \pm$ SEM.

\section{RESULTS}

Table 1 shows the litter size and number for each age group with lung wet weight, protein and DNA content, and protein/ DNA ratio. The protein/DNA ratio increases significantly between $\mathrm{d} 18$ and $\mathrm{d} 20\left(\mathrm{~V}_{1}=1, \mathrm{~V}_{2}=6, \mathrm{~F}=7.906, P=0.031\right)$ with a further significant increase between d 20 and the 3rd postnatal $\mathrm{d}\left(\mathrm{V}_{1}=1, \mathrm{~V}_{2}=7, \mathrm{~F}=17.956, P=0.004\right)$. Because cell protein concentration was not constant over the study period and body water content demonstrates large changes over fetal and early neonatal life (32) enzyme activities are expressed as U/ mg DNA rather than $\mathrm{U} / \mathrm{mg}$ protein or $\mathrm{U} / \mathrm{g}$ lung wet weight.

Table 2 shows the contamination of fetal lung homogenates with blood, and how this may be reduced by careful mincing and washing before tissue homogenization. Table 3 demonstrates the contribution of this blood to total enzyme activity in the lung homogenates, expressed both as $\mathrm{U} / \mathrm{mg}$ DNA and as a percentage of total activity.

Values for G-6-PD, CAT, and GPX after correction for blood contamination are shown in Figure 1. G-6-PD increases progressively from d 18 to term with a further small, but not significant, increase by the $3 \mathrm{rd}$ postnatal $\mathrm{d}$. The increase from $\mathrm{d} 18$ to term is statistically significant $\left(\mathrm{V}_{1}=1, \mathrm{~V}_{2}=8, \mathrm{~F}=8.136, P=0.021\right)$ as is the reduction from $\mathrm{d} 3$ levels to adult levels $\left(\mathrm{V}_{1}=1, \mathrm{~V}_{2}=\right.$ $9, \mathrm{~F}=6.635, P=0.030)$. CAT levels increase significantly from d 18 to $\mathrm{d} 20$ of gestation $\left(\mathrm{V}_{1}=1, \mathrm{~V}_{2}=7, \mathrm{~F}=12.555, P=\right.$ $0.009)$ though not from $\mathrm{d} 20$ to term. There is a further significant increase by the $3 \mathrm{rd}$ postnatal $\mathrm{d}\left(\mathrm{V}_{1}=1, \mathrm{~V}_{2}=9, \mathrm{~F}=6.104, P=\right.$ $0.036)$ then a significant fall to adult levels $\left(\mathrm{V}_{1}=1, \mathrm{~V}_{2}=6, \mathrm{~F}=\right.$ $7.360, P=0.035$ ). GPX increases progressively from $\mathrm{d} 18$ to term with no significant change by the 3 rd d after birth. The increase between $\mathrm{d} 20$ and term is statistically significant $\left(\mathrm{V}_{1}=\right.$ $1, \mathrm{~V}_{2}=8, \mathrm{~F}=10.831, P=0.011$ )

Values for CuZn SOD, Mn SOD, and CYT OX after correction for blood contamination, are shown in Figure 2. CuZn SOD increases from d 18 to term with a significant increase between d 20 and term $\left(\mathrm{V}_{1}=1, \mathrm{~V}_{2}=8, \mathrm{~F}=44.792, P=0.0002\right)$. There is a further increase to $\mathrm{d} 3$, then from $\mathrm{d} 3$ to adult levels. Mn SOD expressed as $\mathrm{U} / \mathrm{mg}$ DNA shows a fall from d 18 to term with a postnatal increase to $\mathrm{d} 18$ fetal levels by the $3 \mathrm{rd}$ postnatal d. All values are higher than those seen in adult lung. Because Mn SOD is primarily a mitochondrial enzyme, values reflect changes in mitochondrial mass. This is not normally a significant variable with adult tissue, however, major changes apparently occur in the lung during late fetal life as indicated by the significant fall in the mitochondrial marker enzyme CYT OX between $\mathrm{d} 18$ and term $\left(\mathrm{V}_{1}=1, \mathrm{~V}_{2}=8, \mathrm{~F}=34 \cdot 387, P=\right.$ $0.0004)$, with a significant postnatal increase by the $3 \mathrm{rd} \mathrm{d}$ of life $\left(\mathrm{V}_{1}=1, \mathrm{~V}_{2}=9, \mathrm{~F}=6.918, P=0.027\right)$. To compensate for these changes (19) Mn SOD levels have also been expressed as U Mn SOD/U CYT OX revealing a significant gestation-related increase in mitochondrial SOD activity between d 18 and term

Table 1. Basic parameters of study groups ( $\bar{m} \pm$ SEM)

\begin{tabular}{|c|c|c|c|c|}
\hline & \multicolumn{3}{|c|}{ Fetal age (d) } & \multirow{2}{*}{$\frac{\text { Age }(\mathrm{d})}{3}$} \\
\hline & 18 & 20 & 22 & \\
\hline Litters ( $n$ ) & 4 & 4 & 6 & 5 \\
\hline Pups/litter $(n)$ & $12 \pm 1$ & $12 \pm 1$ & $9 \pm 2$ & $9 \pm 2$ \\
\hline Lung wet weight/pup (mg) & $18 \pm 1$ & $76 \pm 6$ & $127 \pm 12$ & $174 \pm 7$ \\
\hline Lung DNA/pup $(\mu \mathrm{g})$ & $86 \pm 14$ & $132 \pm 9$ & $247 \pm 32$ & $346 \pm 78$ \\
\hline Lung protein/pup (mg) & $1.3 \pm 0.2$ & $3.4 \pm 0.8$ & $8.1 \pm 1.8$ & $12.9 \pm 2.4$ \\
\hline
\end{tabular}

Table 2. Contamination of lung homogenates with blood $(\bar{m} \pm S E M)$

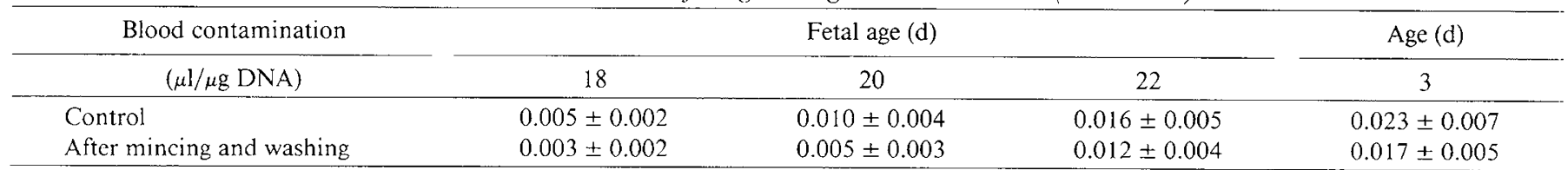

Table 3. The contribution of blood contamination to lung homogenates as $U / m g$ DNA or as percentage of total activity*

\begin{tabular}{|c|c|c|c|c|}
\hline Age & $\begin{array}{c}\text { Superoxide dismutase CuZn } \\
\text { U/mg DNA (\%) }\end{array}$ & $\begin{array}{c}\text { Catalase } \\
\mathrm{U} / \mathrm{mg} \text { DNA }(\%)\end{array}$ & $\begin{array}{l}\text { Glutathione peroxidase } \\
\mathrm{mU} / \mathrm{mg} \text { DNA }(\%)\end{array}$ & $\begin{array}{c}\text { Glucose-6-phosphate } \\
\text { dihydrogenase } \\
\text { mU/mg DNA (\%) }\end{array}$ \\
\hline Fetus, $18 \mathrm{~d}$ & $0.015 \pm 0.009$ & $12 \pm 8$ & $5 \pm 4$ & $3 \pm 2$ \\
\hline Fetus, $20 \mathrm{~d}$ & $0.125 \pm 0.075$ & $21 \pm 13$ & $61 \pm 37$ & $15 \pm 9$ \\
\hline Fetus, $22 \mathrm{~d}$ & $0.456 \pm 0.152$ & $54 \pm 18$ & $179 \pm 60$ & $49 \pm 16$ \\
\hline Newborn, $3 \mathrm{~d}$ & $0.714 \pm 0.210$ & $81 \pm 24 \quad(10)$ & $309 \pm 91$ & $85 \pm 25$ \\
\hline
\end{tabular}

* Values for Mn SOD are not shown because all values were $\ll 1 \%$ of total activity. 


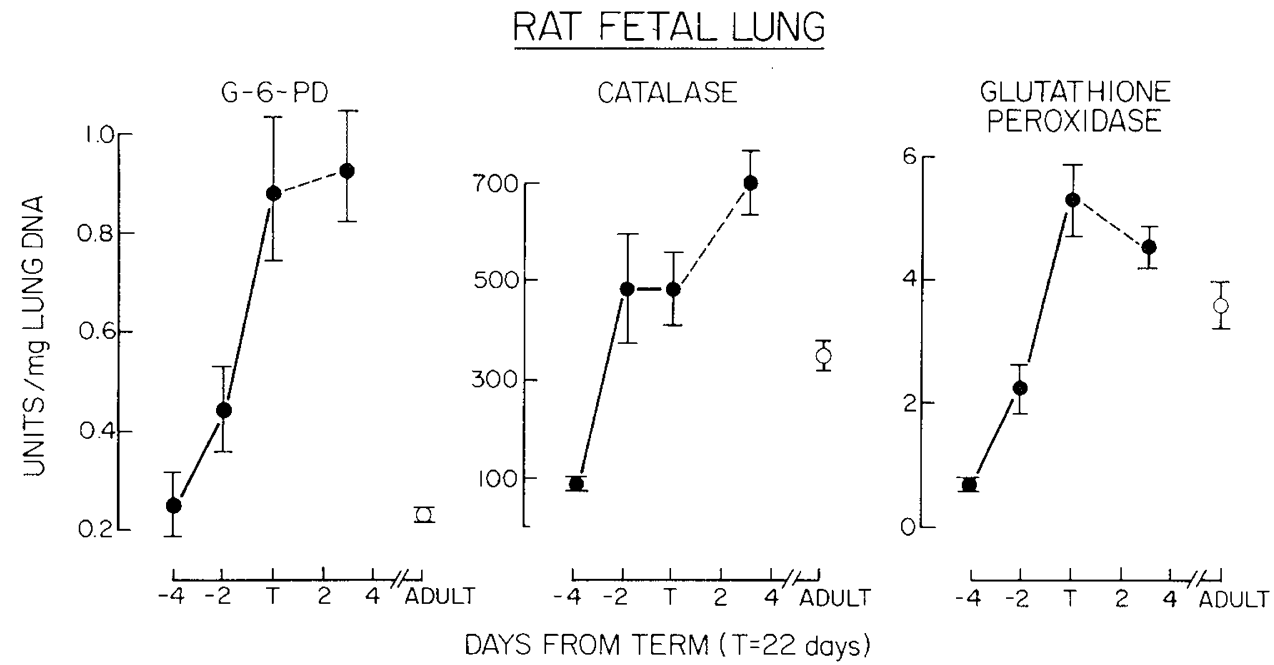

Fig. 1. Activity of glucose-6-phosphate dehydrogenase (G-6-PD), catalase, and glutathione peroxidase in fetal and neonatal lung ( compared with adult controls $(O)$. All values expressed as $\bar{x} \pm$ SEM.
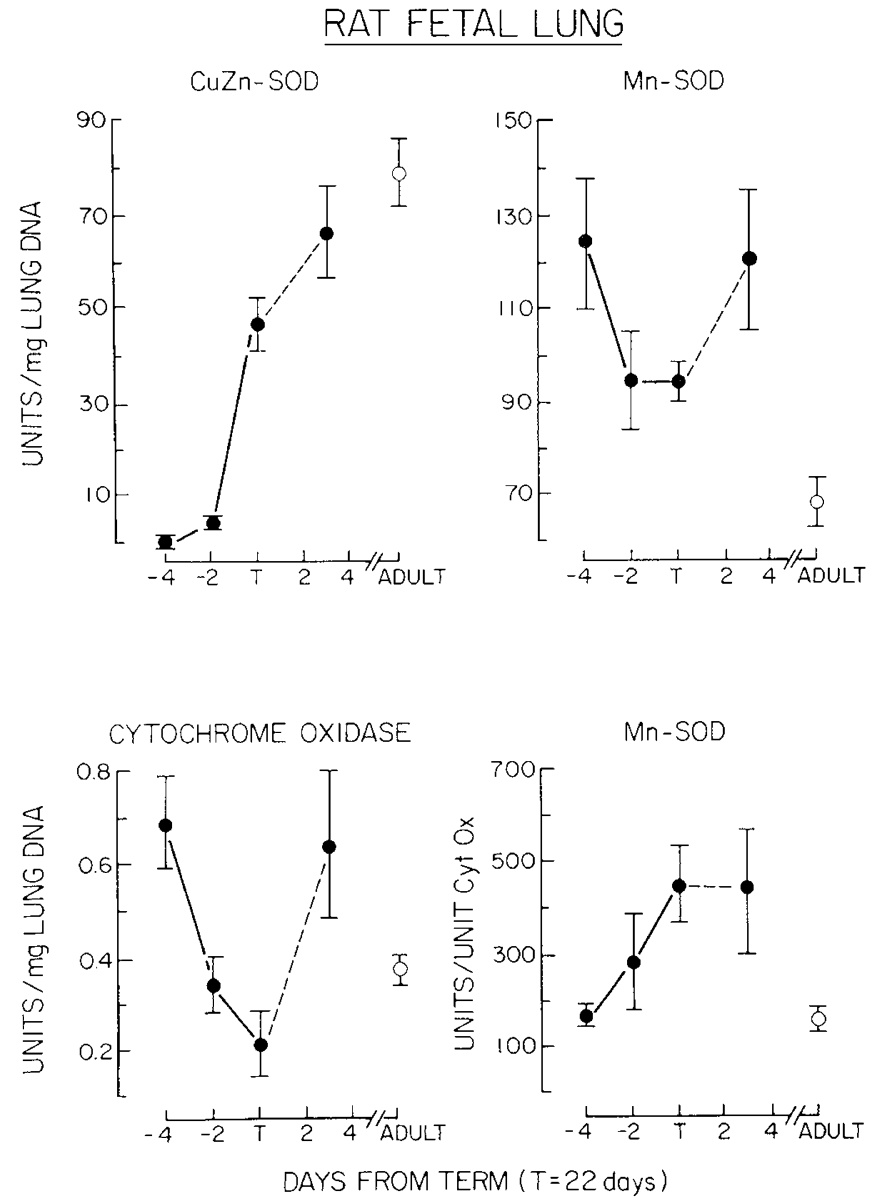

Fig. 2. Activity of CuZn superoxide dismutase (SOD), Mn SOD, and cytochrome oxidase in fetal and neonatal lung $(\bullet)$ compared with adult controls $(O)$. All values expressed as $\bar{x} \pm$ SEM.

$\left(\mathrm{V}_{1}=1, \mathrm{~V}_{2}=8, \mathrm{~F}=8 \cdot 196, P=0.021\right)$ with no significant change by the $3 \mathrm{rd}$ postnatal $\mathrm{d}$. There is subsequently a fall to adult levels.

\section{DISCUSSION}

Litter size after mating of Sprague-Dawley female rats with male hooded rats were similar to those reported previously from

such pairs (25). Lung wet weight, protein, and DNA are somewhat lower than previous reports $(17,22)$ which probably reflects species differences, differences in handling of tissue before weighing, and a different analytical method for DNA estimation. The $35 \%$ increase in protein/DNA between d 20 and 22 of gestation is comparable to the $25 \%$ increase observed by others (17).

Careful washing of minced lung before homogenization reduces blood contamination (Table 2), and the contribution of erythrocyte cytosolic enzymes to total enzyme activity in homogenates. Although blood contamination does increase with gestational age, as would be expected from a developing pulmonary vascular bed, the contribution of blood to total homogenate enzyme activity is generally less than that reported for perfused adult lungs (7). Again, this would be expected because the lungs receive only $\sim 7 \%$ of the cardiac output in utero (24).

Yam et al. (33) reported an antenatal increase in total SOD activity between $\mathrm{d} 20$ and term, with subsequent increases by the 3 rd postnatal $\mathrm{d}$ and further increases in adult life. We have found CuZn SOD to conform to this developmental pattern but not $\mathrm{Mn}$ SOD, which is considerably increased in fetal lung compared with adult lung controls when expressed as either U/mg DNA or U Mn SOD/U CYT OX. The fall in cytochrome oxidase activity in late gestation, with a subsequent postnatal increase, confirms the observations of Warshaw et al. (31) who found that the mitochondrial enzymes cytochrome oxidase and carnitine palmitoyltransferase have similar developmental patterns. The most logical explanation for such changes is that during the phase of rapid lung growth from 18-22 d of gestation, the mitochondrial concentration/cell does not keep up with the rate of cell division. As cell division slows immediately after birth, however, mitochondrial mass/cell increases. Because there are, apparently, changes in mitochondrial mass occurring in the lung in the latter part of gestation, expressing Mn SOD values as U/mg DNA is inappropriate. Using CYT OX activity as a correction factor for these changes (19) reveals that Mn SOD activity follows a developmental profile comparable to that observed for the other antioxidant enzymes. The developmental profile for CAT is similar to that reported as $\mathrm{U} / \mathrm{mg}$ protein by Yam et al. (33), although the apparent leveling off of enzyme activity between $\mathrm{d}$ 20 and 22 of fetal life contrasts with the profile of the other antioxidant enzymes. We have recently demonstrated a gestation-dependent deficiency of CAT activity in maternal lungs as a consequence of iron deficiency of pregnancy (12). It is possible that the failure to increase CAT activity between d 20 and term in the fetal lung is a reflection of reduced iron transport across the placenta. The influence of maternal iron supplements on fetal lung catalase activity has been reported elsewhere (27). The 
perinatal changes in GPX activity were similar to those reported by Yam et al. (33) as $\mathrm{U} / \mathrm{mg}$ protein, but they reported a moderate increase in adult life that was not evident in our adult group. The increase in fetal lung G-6-PD activity with gestation has been suggested by previous reports, and appears to be coincident with a reduction of fetal lung glycogen and increased surfactant synthesis $(17,31)$.

It is apparent that the activity of CAT, GPX, CuZn SOD, Mn SOD, and G-6-PD increase in fetal lung before the onset of air breathing at delivery. Such increases in enzyme activity could be mediated by hormonal changes, or may reflect increased oxygen uptake and metabolic activity of the lung in late gestation (10, 31). The major differences in G-6-PD and Mn SOD activity between fetal and adult lung may also reflect the very different metabolic patterns evident in fetal life (21).

The high levels of G-6-PD in the newborn period would be of value in oxidant stress as a source of NADPH production to facilitate tissue repair and rapid reduction of $\mathrm{H}_{2} \mathrm{O}_{2}$ and possibly lipid peroxides (28). This, along with elevated concentrations of CAT, GPX, and Mn SOD may contribute to the relative tolerance to hyperoxia evident in the young of many species (22). In the fetal rat G-6-PD, GPX, CuZn SOD, and Mn SOD are all lower in $\mathrm{d} 20$ lung than in $\mathrm{d} 22$ (term) lung. In terms of equivalent lung development, $\mathrm{d} 20$ represents approximately $26 \mathrm{wk}$ gestation in the human infant, which is the earliest time for delivery at which a significant survival rate has been attained. This group is particularly prone to hyperoxic exposure and, therefore, development of BPD. Although it is difficult to identify the relative contribution of individual risk factors for the development of $\mathrm{BPD}$, there is some evidence that prematurity per se is of importance $(8,14)$. This could be explained by antioxidant defences which are inadequate for the demands of the hyperoxic environment required to maintain an adequate circulating oxygen tension in the presence of surfactant deficiency.

\section{REFERENCES AND NOTES}

1. Autor, A. P., Frank, L., and Roberts, R. J.: Developmental characteristics of pulmonary superoxide dismutase: relationship to idiopathic respiratory distress syndrome. Pediatr. Res.. 10: 154 (1976).

2. Bergmeyer. H. U.: Zur messung von Katalase-aktivatäten. Biochem. Z., 327 $255(1955)$.

3. Beutler, E.: Glutathione peroxidase. In: Red Cell Metabolism. (Grune and Stratton. New York, 1975).

4. Boyden. E. A.: Development and growth of airways. In: W. A. Hodson: Development of the Lung. pp. 3-35 (Marcel Dekker, New York, 1977).

5. Bucher, J. R.. and Roberts, R. J.: The development of the newborn rat lung in hyperoxia: a dose-response study of lung growth, maturation and changes in antioxidant enzyme activities. Pediatr. Res., 15:999 (1981).

6. Crapo, J. D., Barry, B. E., Foscue, H. E., and Shelburne, J.: Structural and biochemical changes in rat lungs occurring during exposure to lethal and adaptive doses of oxygen. Am. Rev. Respir. Dis., /22: 123 (1980).

7. Cross, C. E., Watanabe, T. T., Hasegawa, G. K., Goralnik, G. N., Roertgen, K. E., Kaizu. T., Reiser, K. M., Gorin, A. B., and Last, J. A.: Biochemical assays in lung homogenates: artifacts caused by trapped blood after perfusion. Toxicol. Appl. Pharmacol., 48: 99 (1979).

8. Edwards, D. K., Dyer, W. M., and Northway, W. H.: Twelve years' experience with bronchopulmonary dysplasia. Pediatrics, 59:839 (1977).

9. Erwin. B. G.. Stoscheik, C. M., and Florini, J. R.: A rapid fluorimetric method for the estimation of DNA in cultured cells. Anal. Biochem., 110:291 (1981)

10. Frank, L. and Masaro, D.: Oxygen toxicity. Am. J. Med., 69: 117 (1980).

11. Freeman, B. A. and Crapo, J. D.: Hyperoxia increases oxygen radical produc- tion in rat lungs and lung mitochondria. J. Biol. Chem.. 256: 10986 (1981) 12. Freeman, B. A. and Tanswell, A. K.: Lung catalase deficiency in pregnant rats increases susceptibility to toxicity of $60 \%$ oxygen. Am. Rev. Respir. Dis. (abstract), 125: 228 (1982)

13. Hayatdavoudi, G., O'Neil, J. J., Barry, B. E., Freeman, B. A., and Crapo, J. D.: Pulmonary injury in rats following continuous exposure to $60 \% \mathrm{O}_{2}$ for 7 days. J. Appl. Physiol., 51: 1220 (1981).

14. Hodson, W. A., Truog, W. E., Mayock, D. E., Lyrene, R., and Woodrum, D. E.: Bronchopulmonary dysplasia: the need for epidemiologic studies. J. Pediatr. 95: 848 (1979).

15. Kehrer, J. P. and Autor, A. P.: Age-dependent lipid peroxidation in neonatal rat lung tissue. Arch. Biochem. Biophys., 181: 73 (1977).

16. Lowry, O. H., Rosebrough, N. J., Farr, A. L., and Randall, R. J.: Protein measurement with the Folin phenol reagent. J. Biol. Chem., 193: 265 (1951).

17. Maniscalco, W. M. Wilson, C. M. Gross, I. Gobran, L. Rooney, S A and Warshaw, J. B.: Development of glycogen and phospholipid metabolism in fetal and newborn rat lung. Biochim. Biophys. Acta, 530: 333 (1978).

18. Mavelli, I., Autuori, F., Dini, L., Spinedi, A., Ciriolo, M. R., and Rotilio, G.: Correlation between superoxide dismutase, glutathione peroxidase and catalase in isolated rat hepatocytes during fetal development. Biochem. Biophys. Res. Comm., 102:911 (1981).

19. Mavelli, I., Rigo, A., Federico, R., Ciriolo, M. R., and Rotilio, G.: Superoxide dismutase, glutathione peroxidase and catalase in developing rat brain. Biochem. J., 204: 535 (1982).

20. McCord. J. M.: Superoxide. superoxide dismutase and oxygen toxicity. Rev. Biochem. Toxicol., I: 109 (1979).

21. Milley. J. R.. and Simmons. M. A.: Metabolic requirements for fetal growth. Clin. Perinatol., 6: 365 (1979).

22. Roberts, R. J.: Employment of pulmonary superoxide dismutase, catalase and glutathione peroxidase activity as criteria for assessing suitable animal models for studies of bronchopulmonary dysplasia. J. Pediatr., 95:904 (1979).

23. Rudolph, A. M.: In: Congenital Diseases of the Heart. (Year Book Medical Publishers, Inc.. Chicago, 1974).

24. Rudolph, A. M. and Heymann, M. A.: Fetal and neonatal circulation and respiration. Annu. Rev. Physiol., 36:187 (1974).

25. Smith, B. T.: The role of pulmonary corticosteroid 11-reductase activity in lung maturation in the fetal rat. Pediatr. Res., 12: 12 (1978).

26. Sottocasa, G. L., Kuylenstierna, B., Ernster, L., and Bergstrand, A.: An electron transport system associated with the outer membrane of liver mitochondria. A biochemical and morphological study. J. Cell Biol., 41: 124 (1967)

27. Tanswell, A. K. and Freeman, B. A.: Pulmonary antioxidant enzyme maturation in the fetal and neonatal rat. II. The influence of maternal iron supplements upon fetal lung catalase activity. Pediatr. Res., in press.

28. Tierney, D., Ayers, L., Herzog, S., and Yang, J.: Pentose pathway and production of reduced nicotinamide adenine dinucleotide phosphate. Am. Rev Respir. Dis., 108: 1348 (1973).

29. Turrens, J. F., Freeman, B. A., and Crapo, J. D.: The effect of hyperoxia on $\mathrm{H}_{2} \mathrm{O}_{2}$ production by porcine lung mitochondria and microsomes. Arch. Biochem. Biophys., 217:411 (1982)

30. Van Hien, P., Kovács, K., and Matkovics, B.: Study of superoxide dismutase activity change in human placenta of different ages. Enzyme. 18: 341 (1974)

31. Warshaw, J. B., Terry, M. L., and Ranis, M. B.: Metabolic adaptation in developing lung. Pediatr. Res., 14: 296 (1980).

32. Widdowson. E. M.: Changes in body proportions and composition during growth. In: J. A. Davis, and J. Dobbing: Scientific Foundations of Paediatrics. pp. 153-163 (Heinemann, London, 1974).

33. Yam, J., Frank, L., and Roberts, R. J.: Age-related development of pulmonary antioxidant enzymes in the rat. Proc. Soc. Exp. Biol. Med., 157: 293 (1978).

34. Yoshioka, T., Utsumi, K., and Sckiba. K.: Superoxide dismutase activity and lipid peroxidation of the rat liver during development. Biol. Neonate., 32 . 147 (1977).

35. Requests for reprints should be addressed to: Dr. A. K. Tanswell, Research Institute. St. Joseph`s Hospital, 268 Grosvenor Street, London, Ontario N6A 4V2. Canada.

36. BAF was a Queen's Quest visiting scholar during the performance of the initial part of these studies.

37. Supported by grants \#DG 207 and MA 7867 from the Medical Research Council of Canada (AKT) and \#HL-29784 from the National Institutes of Health (BAF)

38. Received for publication October 1, 1982.

39. Accepted for publication September 20, 1983. 